\title{
El Derecho institucional en el realismo metódico de Vallet de Goytisolo
}

\author{
The Institutional Law in the Methodical Realism \\ of Vallet de Goytisolo
}

\author{
Adolfo SÁNCHEZ HidALgO \\ Universidad de Córdoba \\ jizsahia@uco.es
}

RECIBIDO: 22/06/2017 / ACEPTADO: 03/04/2018

\begin{abstract}
Resumen: Este artículo tiene por objeto el estudio de la idea de derecho institucional en la metodología jurídica de Vallet de Goytisolo, analizar sus orígenes doctrinales y su naturaleza. Asimismo, se señalará su funcionalidad teórica y práctica para la comunidad de los juristas, es decir, la importancia de una concepción institucional del derecho en la determinación negocial y conflictual del derecho, en la creación de las leyes y en el trabajo hermenéutico de los teóricos del derecho. Finalmente, se analizará críticamente la coherencia teórica, utilidad práctica y encaje normativo de esta visión institucional del Derecho.
\end{abstract}

Palabras clave: derecho institucional; Vallet de Goytisolo; ontología; realismo metódico; sistema jurídico; actividad negocial; teóricos del derecho.

\begin{abstract}
This paper aims to the study of the institutional law in the juridical methodology of Vallet de Goytisolo, just as is necessary to analyse his doctrinal origins and his nature. Furthermore, it will be pointed his theoretical and practical functionality for the community of jurist, that is, the importance of an institutional conception of Law in the business activity and the judicial dispute, the same as in the law creation and in the hermeneutic job of Law theorists. Finally, it will be analysed the theoretical coherence, the practical utility and the normative fitting of this institutional vision of Law.
\end{abstract}

Keywords: institutional law; Vallet de Goytisolo; ontology; methodical realism; law system; business activity; law theorists.

\section{INTRODUCCIÓN. ORIGEN DE LA EXPRESIÓN «DERECHO INSTITUCIONAL»}

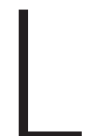

a idea de institución jurídica ha tenido un desarrollo destacado a principios del siglo XX en la doctrina francesa (Hauriou, Renard, Gurvitch), en Alemania (Schmitt, Larenz) y tuvo una gran acogida en España a raíz de la obra de Ruiz Giménez La concepción institucional del Derecho. También, más recientemente, se ha relanzado el interés por una idea institucional del Derecho gracias a las obras de Neil Maccormick (An instituional Theory of Law, Institutions of Law). Este gran cuerpo de doctrina se centra principalmente en la institución entendida como persona, es decir como asociación de individuos y de manera muy incidental se ocupa de la institución entendida 
como figura ${ }^{1}$. Ahora bien, pese a la importancia que ha adquirido el concepto de institución-persona, la temática de este escrito tiene por objeto la institución entendida como figura jurídica y, más concretamente, el análisis de la idea de institución en el pensamiento ius-privatista de dos afamados juristas catalanes: Ramón María Roca Sastre (1899-1979) y Juan Berchmans Vallet de Goytisolo (1917-2011).

El compuesto «derecho institucional» es utilizado por Roca Sastre en 1940 con motivo del trabajo titulado «Crítica institucional del Código Civil» publicado en la Revista Crítica de Derecho Inmobiliario ${ }^{2}$ y esta misma denominación sería reafirmada 10 años después en el prólogo a la obra de Puig Brutau Estudios de Derecho comparado. La doctrina de los actos propios ${ }^{3}$. Esta expresión evoca, según el jurista de Tárrega, la fuente fecunda de concepciones jurídicas que debe nutrir al legislador y al juez cuando dicten las leyes y las sentencias, respectivamente. Vallet recoge el testigo de Roca Sastre y desarrolla con mucha más ambición que su maestro la idea de institución, ésta es configurada como la clave de bóveda de su particular concepción de la metodología jurídica. Más aún, es en la idea de institución donde encuentra Vallet el armazón de su concepción funcional y estructural del Sistema ${ }^{4}$. A lo largo de este estudio desarrollaremos su idea de institución jurídica y su funcionalidad teóricopráctica para la actividad de los juristas.

1 Hauriou, M., La Teoría de la Institución y de la Fundación (ensayo de vitalismo social), Abeledo Perrot, Buenos Aires, 1968; REnard, G., La theorie de l'institution. Essai d'ontologie juridique, Sirey, Paris, 1930; GuRvitch, G., l'experience juridique et la philosophie pluraliste du droit, Pedone, Paris, 1933; Sснмiтт, C., Sobre Los tres modos de pensar la ciencia jurídica, Tecnos, Madrid, 1996; LaRenz, K., La filosofía contemporánea del derecho y del Estado, Reus, Madrid, 2008; RUIZ GiméneZ, J., La concepción institucional del Derecho, Instituto de Estudios Políticos, Madrid, 1944; MacCormick, N. y Weinberger, O., An institutional Theory of Law, Springer, Dordrecht, 1986; MACCormick, N., Instituciones del derecho, Marcial Pons, Madrid, 2011.

2 Roca Sastre, R., «Crítica institucional del Código Civil», Revista Crítica de Derecho Inmobiliario, n. ${ }^{\circ} 148$ (1940), pp. 497-515.

3 ID., «Prólogo», PUtg Brutau, J., Estudios de derecho comparado. La doctrina de los actos propios, Ariel, Barcelona, 1951, pp. 13 y ss.

4 Como el término «sistema» admite significados diversos, es necesario señalar que, en adelante, será utilizado de acuerdo con la posición metódicamente realista de Vallet de Goytisolo. En este sentido, la idea de sistema responde a una visión orgánica del ordenamiento jurídico, el cual es entendido como una realidad compleja tendente (diversidad ordenada) a la configuración de lo que es justo en cada caso concreto. El sistema se traduce en un orden jurídico en continuo proceso de perfección, ya sea en su dimensión estructural o dogmática (Ciencia expositiva y explicativa del Derecho); como en su dimensión dinámica o práctica (Determinación prudencial del Derecho). 
Una vez presentados los sujetos principales de nuestra investigación y el objeto de la misma, puedo introducir al lector en el plan expositivo de este escrito, adelantándole qué descubrirá en él. Es casi obligado iniciar con el estudio de la institución jurídica, indagar cuál es su naturaleza en las diferentes concepciones que se han sucedido sobre la misma; a estas reflexiones le seguirá la descripción y análisis de la idea de «derecho institucional» en Roca Sastre, que servirá como punto de partida para comprender la posición de Vallet; a continuación, examinaremos con detalle la dimensión teórica y práctica de la institución jurídica en el realismo metódico de Vallet de Goytisolo; y concluiremos este trabajo exponiendo críticamente la coherencia y oportunidad de su tesis, así como el encaje positivo de la misma.

\section{A PROPÓSITO DE LA NATURALEZA DE LA INSTITUCiÓN JURÍDiCA}

Prudentemente y en consonancia con el espíritu observador que le define en el decurso de los siglos, nos dejaba escrito Aristóteles: «En efecto, en lo que se refiere a las acciones, razonar en general es razonar en buen grado en el vacío, mientras que estando encima de los casos particulares hay posibilidad de acercarse más a la verdad. Las acciones, efectivamente, no miran más que a las cosas particulares; nuestras teorías deben, pues, armonizarse con ellas $»^{5}$. En esta reflexión clásica tenemos un pequeño apunte de la que podemos llamar una filosofía metódicamente realista, esto es, Aristóteles nos recomienda que toda teoría debe partir del conocimiento de la cosa particular y, en consecuencia, el valor de la teoría dependerá de su proximidad a la cosa (adecuación del intelecto a la cosa, decía Santo Tomás).

Dicho de otra manera, todo ejercicio intelectual debe partir de un estudio ontológico del objeto, cosa o acontecimiento. Sin embargo, estas tres palabras no son sinónimas y la utilización de una u otra ya supone una toma de posición. Si nos servimos de la voz «objeto» nos referimos a «algo» que ocupa nuestra atención y que, por tanto, se define como la proyección de nuestro entendimiento; si utilizamos la palabra «cosa» nos referimos a «algo» que está ahí en el mundo, que existe en la realidad (res); y si empleamos la palabra «acontecimiento» queremos representar la idea de que «algo» ha sucedido, ha sido hecho, «factum esse».

5 ARISTóteles, Obras, Ética a Nicómaco, 2, 6, 1107 a), Aguilar, Madrid, 1982, p. 309. 
Ahora bien, «algo» puede ser observado en movimiento o estáticamente, la diferencia entre la «cosa» y el «acontecimiento», es que las cosas están y los acontecimientos se mueven. El ser de las cosas es una realidad estática y el ser de los acontecimientos una realidad dinámica, el «objeto»-al contrario- ni está, ni se mueve.

La línea de pensamiento metódicamente realista (también podemos denominarla aristotélico-tomista) presupone una metodología subjecta materia, es decir, el estudio de la naturaleza de la cosa individual y, última ratio, su posición en el orden general de la naturaleza (naturaleza de las cosas), revelándose así la ontología como ciencia primera ${ }^{6}$. La ontología es, por así decirlo, una ciencia estática que trata de conocer la naturaleza de las cosas y, como escribe Aristóteles, la naturaleza de la cosa es esa misma cosa una vez alcanzada su perfección ${ }^{7}$. Bien y ser se identifican, pues, las cosas las conocemos por su realización, lo que la cosa es y no su vocación de ser (potencia del ser), o, lo que ha dejado de ser (corrupción del ser). Aristóteles utiliza la palabra physis (naturaleza), ésta viene del verbo phisey que significa germinar, para darnos a entender que la naturaleza es el orden dinámico de cuanto acontece, tanto de lo que está llamado a ser, como lo que es y lo que una vez ha sido ha comenzado su proceso de degeneración ${ }^{8}$. La física tiene por objeto el estudio de los acontecimientos (phaenomenon), pero sólo en la medida que nos revelan el ser de las cosas o el momento de su perfección. El acontecimiento tiene «valor» en la medida que nos manifiesta el ser, lo que no ocurre siempre, sino sólo cuando el ser alcanza su bien.

Esta manera de conocer el ser de las cosas colisionaba frontalmente con el idealismo platónico (realismo sólo si aceptamos su lenguaje), pues, no soportaba la variabilidad de la realidad sensible, que para él no era sino una copia imperfecta del mundo de las ideas. Allí el ser racional encontraba las formas puras de la realidad, las ideas, siempre unívocas y eternas9. La idea era el «objeto» abstracto de nuestro intelecto que nos permitía dotar de racionalidad y

6 Carpintero Benítez, F., «Métodos científicos y método del derecho: una historia superada», Persona y Derecho, n. ${ }^{\circ} 62$ (2010), p. 49.

7 Aristóteles, Política, I, 1, 1252 b), Instituto de Estudios Políticos, Madrid, 1970, p. 3.

8 Hittinger, R., «Natural Law and Virtue: Theories at Cross Purposes», Natural Law Theory, Oxford University Press, 1992, p. 43. «Nature designates not only the quiddities of things - the formal cause that wich makes a thing what it is - but more importantly the finality governing completions».

9 Medina Morales, D., «El derecho como idea de orden permanente en Hans Kelsen», Persona $y$ Derecho, n. ${ }^{\circ} 62$ (2010), p. 82. 
orden a la realidad sensible, mutable, imperfecta y caótica. La realidad sensible, los acontecimientos y las cosas, sólo tienen valor en la medida que se corresponden con el objeto de nuestro entendimiento: las formas puras del mundo de las ideas. Quiere esto decir que el bien de las cosas se halla fuera de la realidad física de las mismas, en su imagen abstracta e ideal del mundo de las ideas. De manera absolutamente opuesta a la línea aristotélica, el conocimiento no será la adecuación del intelecto a la cosa, sino la adecuación de la cosa al intelecto.

La filosofía clásica osciló hasta el siglo XV entre estos dos polos: idealismo y realismo. La Escuela de los Nominales, principalmente Ockham, quebró el modo clásico de entender la filosofía, pues, al negar la posibilidad humana de conocer un orden racional en las cosas, negó la relación de identidad aristotélica entre ser y bien. La racionalidad humana solo puede conocer las sustancias en su estricta individualidad, en su ser fenoménico sin que quepa inferir géneros, sustancias segundas o especies, ni universales como la «naturaleza de las cosas ${ }^{10}$. Si en las cosas no es posible encontrar racionalmente su bien, no tienen naturaleza, tan sólo nos queda su realidad como empiria, esto es, «objeto» de la experiencia. La razón (res cogitans) fue apartada del mundo sensible (res extensa) y en su lugar se elevaba la experiencia como criterio rector de la ciencia, al igual que la razón fue apartada de la ética y en su lugar se colocó la voluntad. El empirismo, gracias a Oxford, se convirtió en el nuevo realismo científico y el imperio de la voluntad en la premisa del conocimiento ético ${ }^{11}$.

La modernidad es heredera de esta ruptura y, en adelante, toda corriente filosófica comparte la premisa gnoseológica empirista señalada por Hume como falacia naturalista, por la cual no es posible extraer postulados de deber ser del mundo del ser. Esta idea sería reafirmada por la escuela de Marburgo, que trató de extender la ley causal de las ciencias naturales a la ciencia jurídica mediante la llamada regla técnica ${ }^{12}$. El empirismo como método del conocimiento científico, ahora llamado positivismo, se había extendido más allá

10 Vallet de Goytisolo, J., Metodología de la Ciencia expositiva y explicativa del Derecho. La ciencia del derecho a lo largo de su historia, vol. I, Fundación Cultural del Notariado, Madrid, 2000, pp. 195-199. Vallet señala que el nominalismo de Ockham tan sólo dejo abiertas tres vías al saber humano: a) la teologista que rompe la unión de Dios y naturaleza (Scoto, Ockham, Lutero y Calvino); la metafísica idealista o esencialista que solo admite la existencia de lo individual (Ockham, Rimini, Descartes, Suárez, Leibniz); y la vía empirista que limita el conocimiento científico al estudio del factum (Bacon, Ockham, Hume).

11 Ibid., p. 200.

12 Robles Morchon, G., Teoría del Derecho. Fundamentos de Teoría Comunicacional del Derecho,

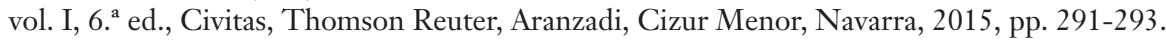


de las ciencias naturales al ámbito de las ciencias normativas y, claro está, la labor del científico del derecho no es prescribir el Derecho que debe ser sino describir el Derecho tal cual es ${ }^{13}$. Es aquí donde el positivismo se divide en sociológico y normativo, dependiendo de cómo se entienda el Derecho como fenómeno social o fenómeno normativo ${ }^{14}$. Aún cabría incluir una tercera categoría de positivismo, el judicial, que considera como primer acontecimiento la decisión judicial y sobre ella fundamenta la ciencia jurídica ${ }^{15}$.

Este aventurado decurso histórico (disculpe el lector las muchas omisiones que habrá encontrado) nos permite individualizar tres grandes cauces para la comprensión de la institución jurídica: A) la perspectiva del realismo metódico; B) la perspectiva idealista; y C) la perspectiva empirista que, a su vez, debe dividirse en normativa, histórico-sociológica y judicial.

\section{Una visión realista (clásica) de la institución jurídica}

En virtud de las premisas gnoseológicas antes señaladas, la institución jurídica ha de ser entendida como una unidad plural de sustancias individuales cuyo suceder fenoménico nos revela un orden intrínseco. La teoría de las unidades plurales es desarrollada por Santo Tomás en la Tercia Parte de la Summa Theologica y distingue tres grandes tipos de unidades: a) la unión de dos o más cosas perfectas que conservan su integridad respectiva; b) la unión de cosas perfectas en sí mismas pero transformadas al unirse; y c) la unión de realidades imperfectas en sí mismas pero perfectas en la conjugación ${ }^{16}$. La institución se correspondería con el primer tipo de unidades plurales, es decir, la unión ordenada de sustancias individuales perfectas ${ }^{17}$. Es decir, la institución -así entendida- sería una unidad plural de hechos jurídicos, relaciones jurídicas, principios jurídicos

3 Ibid., p. 145.

14 Ibid., pp. 328-329.

15 VAllet de GoYTisolo, J., «¿Qué es el realismo? Diversas perspectivas con las cuales se enfoca su significado?», Anales de la real Academia de Ciencias Morales y Políticas, n. ${ }^{\circ} 78$ (2001), p. 604.

16 Santo Tomás, Suma Teológica, III, q. 2, 1, vol. V, BAC, Madrid, 1994, pp. 66-67.

17 En cambio, debemos rechazar las otras dos posibilidades de unidades plurales. No se trataría de la unión de cosas perfectas y transformadas al unirse, porque las relaciones, hechos, principios y pautas no se transforman en virtud de su pertenencia a la institución, sino que se «ordenan» conservando su individualidad. No se trataría tampoco de la unión de realidad imperfectas pero perfectas en la conjugación, porque las relaciones, hechos, principios y pautas no se definen por su pertenencia a la institución, al contrario tienen un valor propio e individual, de modo que la institución no es más que la manifestación ordenada de ese conjunto de realidades individuales. 
y pautas de valor que en su realización nos revelan un orden inmanente. Los hechos, relaciones, principios y pautas tienen su propio ser (ontos), pero al observarlos conjuntamente en el acontecer descubrimos que poseen un orden o razón común (logos) y, en tanto, forman una unidad más amplia. A esta unidad, podemos denominar institución jurídica y así creo es entendida por los primeros teóricos juristas romanos quienes fueron comprendiendo la compleja vida negocial de Roma mediante la «individualización ${ }^{18} \gg$ de sucesivas instituciones o figuras jurídicas ${ }^{19}$. En suma, desde la perspectiva del realismo metódico la noción de institución jurídica es el elemento central de la ontología: de lo individual a lo plural, de lo plural a lo universal ${ }^{20}$. La institución es una categoría cognitiva intermedia que permite la aprehensión de lo individual, ordenar lo plural y aproximativamente guiar nuestro intelecto hacia lo universal.

\section{La visión idealista de la institución jurídica}

Quizás la característica más genuina del idealismo sea la afirmación radical de la existencia de las ideas y formas puras, bien como auténticas manifestaciones del ser de las cosas (idealismo objetivo) ${ }^{21}$, bien como formas puras o categorías del pensamiento desde las que comprender la realidad sensible (idealismo subjetivo) ${ }^{22}$. En este último caso, la institución quedará perfilada como una categoría conceptual desde la que comprender o «someter» la vida

18 Entiéndase «individualización» en el sentido expuesto de unir lo diverso (hechos, relaciones, principios y pautas) en lo uno (institución).

19 KASER, M., En torno al método de los juristas romanos, Universidad de Valladolid, 1964, pp. 33-35.

20 Renard, G., La theorie de l'institution. Essai d'ontologie juridique, Sirey, Paris, 1930, p. 80. «L' Ordre juridiquee - je m'excuse de répéter -, c'est la coaptation des activités individuelles aux fins des communauté et des communautés élémentaires aux fins des communautés supérieures: ubi societas, ibi ju; ubi jus ibi societas. A ce point, l'institution devenait nécessairement le principal objectif de mes investigations ultérieures».

21 No es casual que el platonismo sea una influencia notable en los autores adscritos al idealismo objetivo (Hegel, Larenz), así como en otras posiciones similares camufladas de realismo (Husserl, Reinach). En definitiva, unos y otros, conciben la idea (espíritu objetivo, espíritu del pueblo, orden concreto de vida, intuición eidética, conceptos a priori) como el «verdadero ser de las cosas» más o menos visible, más o menos oculto, en su manifestación fenoménica.

22 El idealismo subjetivo encuentra su origen en la escisión cartesiana entre res cogitans y res extensa, pues, al afirmar la incontrovertible evidencia del cogito ergo sum, Descartes, convierte al pensamiento en lo único definitivamente real y la realidad sensible en un campo fértil para la actuación de la razón geométrica. Las cosas dejan de tener una existencia propia y pasan a ser considerados «objetos», es decir, las cosas existen en la medida que son pensadas. La conciencia subjetiva es la que da vida o define la realidad inerte de los «objetos». 
jurídica, así aparece -por ejemplo- en el pensamiento de Ihering quien las define como: «cuerpos jurídicos» 0 «seres jurídicos, que concebimos y animamos con la idea de una existencia y una vida individuales», «objeto y fin de la construcción jurídica $\gg^{23}$. En otros términos podría sostenerse que las instituciones son herramientas dogmáticas diseñadas con el objetivo de someter la variada y multiforme vida social a las formas puras del intelecto ${ }^{24}$.

En el «idealismo subjetivo» las instituciones son categorías mentales que sirven como herramienta para ordenar la realidad. En cambio, el «idealismo objetivo» va más allá de esta instrumentalización dogmática y propone una pseudo-ontología idealista, en función de la cual, las instituciones son los modos de manifestación de la «idea» en la realidad sensible, en la condicionalidad histórica, en la experiencia vital del pueblo o, simplemente por compendiar, en la «maltrecha» realidad fenoménica. Esta concepción es evidente en Larenz ${ }^{25}$, sin embargo, se encuentra algo más neutral en la escuela fenomenológica ${ }^{26}$. Dicho lo cual, no sería justo preterir la importancia que el pensamiento tipológico ha tenido en el desarrollo de la ciencia jurídica, así como -es obligado resaltarlo-su proximidad a la idea de unidades plurales de Tomás ${ }^{27}$. En consecuencia, puede constituir una herramienta especialmente apta para el análisis estructural y funcional de la institución jurídica ${ }^{28}$.

\section{La institución jurídica desde la perspectiva positivista}

Con anterioridad, he afirmado que el positivismo es una forma de empirismo y dependiendo de cuál sea el acontecimiento que tomemos por empiria resultará una u otra forma de positivismo. El normativista hace de la norma la

23 Ihering, R., Espiritu del Derecho Romano, Comares, Granada, 1998, pp. 560. Ihering avanza la idea de institución jurídica como ser individual o cuerpo jurídico del Derecho, que la Ciencia -jurisprudencia- ha de recoger como elemento clave para la reconstrucción conceptual y sistemática de la ley positiva.

24 Ibid., p. 29.

25 LARENZ, K., La filosofía contemporánea..., op. cit., p. 282. «El orden concreto es realidad, no mera representación normativa; pero es realidad, no en el sentido del concepto positivista de la realidad, sino en el de la realización del espíritu jurídico del pueblo en la vida de la comunidad».

26 Hernández Gil, A., Metodología de la ciencia del Derecho, Obras completas, vol. V, Espasa, Madrid, 1988, pp. 221-225.

27 EngIsCH, K., La idea de concreción en el derecho y en la ciencia jurídica actuales, Universidad de Navarra, 1968, p. 418.

28 VAllet de Goytisolo, J., «Conceptos y tipos. Razonamiento conceptual y razonamientos tipológicos», Anales de la Real Academia de Furisprudencia y Legislación, n. ${ }^{\circ} 34$ (2003), p. 29. 
experiencia básica del Derecho, de modo que la institución jurídica sólo puede entenderse como un conjunto de normas referidas a una misma situación. Ejemplo de esta concepción normativa de institución es la obra de Stammler, quien afirma: «por institución jurídica se entiende la reproducción de una relación jurídica que se presenta con idéntico contendido en diferentes normas de Derecho» ${ }^{29}$. Desde posiciones empíricas que conciben la historia o el contexto social sencillamente como un hecho, esto es una realidad dada carente de valor, la institución jurídica es un producto histórico en constante proceso de desarrollo ${ }^{30}$. Dentro de esta línea de pensamiento podemos destacar a Bonfante con su denominado método evolucionista ${ }^{31} \mathrm{y}$, no sin polémica, creo que también a Schmitt ${ }^{32}$. Claro está, debe destacarse a Savigny, en tanto fundador de la Escuela histórica. El jurista alemán formula una idea histórico-sistemática de la institución, en cuya virtud la institución es un producto cultural e histórico entretejido en la legislación nacional y su comprensión sistemática exige casar esa dimensión histórica con su realidad normativa ${ }^{33}$. Finalmente, escogeremos a Pound como muestra del que hemos llamado positivismo judicial. Para este autor las instituciones jurídicas son sencillamente conceptos o categorías de calificación jurídica, fruto de los escritores y profesores del derecho $^{34}$. El factor decisivo de su aplicabilidad en el derecho «real» dependerá del arbitrio discrecional del juez y de la utilidad que le ofrezcan estas figuras jurídicas para «calificar»o «integrar» los hechos del caso ${ }^{35}$.

Ahora que está cerrada esta pequeña panorámica acerca de la naturaleza de la institución jurídica, debo concluir -anticipadamente- que todas estas visiones diferentes de la institución jurídica consiguen reflejar rasgos inherentes al ser de la institución; pero, se trata de visiones incompletas, porque todas estas tesis son herederas de una determinada posición gnoseológica, que

29 Stammler, R., Tratado de Filosofía del Derecho, Reus, Madrid, 2007, p. 405.

30 Hernández GIL, A., Metodología de la ciencia..., op. cit., p. 55.

31 Bonfante, P., Instituciones de Derecho Romano, Reus, Madrid, 1959, p. 4. El autor nos habla de «leyes orgánicas de la evolución jurídica».

32 SchmitT, C., Sobre los tres modos de pensar la ciencia jurídica, Tecnos, Madrid, 1996, p. 76. Quizás pueda considerarse a Schmitt como un autor historicista, de su lectura se infiere que la historia es el suceder de cambios en la comunidad política. $\mathrm{El}$ «orden concreto de vida» es, en definitiva, la concreta experiencia histórico-vitalista de una determinada comunidad.

33 Savigny. F., Sistema del Derecho Romano Actual, Centro Editorial Góngora, Madrid, 1878-1879, p. 188.

34 Pound, R., «Hierarchy of sources and forms in different Systems of Law», Tulane Law Review, vol.7, issue 4 (1932-1933), p. 484.

35 Puig Brutau, J., La jurisprudencia como fuente del derecho, Bosch, Barcelona, 2006, p. 228. 
limita la completa aprehensión de la realidad. Por esta razón juzgo, como método más adecuado para el estudio de la institución jurídica, el ofrecido por el realismo clásico porque abraza la multiplicidad e infinita variedad de los fenómenos, sin renunciar a la posibilidad racional de hallar un orden en su eterno devenir. Así, desde la perspectiva del realismo clásico, el filósofo del derecho debe dedicar sus esfuerzos a la ontología jurídica, esto es, tratar de hallar el logos (razón común o principio dador de orden) en el entramado multiforme y complejo de los fenómenos individuales: cosas, hechos, actos y relaciones. En ese esfuerzo, toda información será útil: los principios jurídicos, las pautas de valor, las construcciones dogmáticas, los elementos históricos y tradicionales, la correspondencia normativa y, por supuesto, los actos de decisión de los juristas prácticos. No se trata de buscar la prevalencia de unos elementos sobre otros, sino de hallar el principio ordenador que haga de todos estos elementos una unidad, la institución jurídica.

\section{ROCA SASTRE Y EL «DERECHO INSTITUCIONAL» O UNA DOGMÁTICA ABIERTA A LA EXPERIENCIA JURÍDICA}

Ramón María Roca Sastre había crecido como jurista en un ambiente académico dominado por la jurisprudencia de conceptos y esta influencia determina en gran medida sus reflexiones acerca del derecho ${ }^{36}$. Sin embargo, como jurista práctico había experimentado la rica vida negocial de Cataluña, lo que sin duda tenía un eco importantísimo en su obra científica ${ }^{37}$. Roca es un autor en el que la erudición y el pragmatismo convergen y, gracias a ello, consigue superar el rígido dogmatismo imperante en su época y aproximarse

36 Vallet de Goytisolo, J., «Ramón Roca Sastre», Anuario de Derecho Civil, vol. 32, n. 4 (1979), p. 609.

37 Ramón Roca Sastre (1899-1979) nació en Tárrega, se graduó en Derecho en 1821 en la Universidad de Barcelona. En 1923 ingresó por oposición en el Cuerpo de Registradores y desempeña los registros de Belchite, Sort, Fraga y Gandesa. En 1932 ganó plaza en la oposición de Notarías y en 1933 ganó plaza también en Judicatura. En el año 1936 es designado por oposición magistrado del Tribunal de Casación de Cataluña. Además, Roca Sastre ejerció como abogado entre los años 1939 a 1944, año en el obtuvo la notaría de Barcelona que desempeñó hasta su jubilación. Ha sido académico de la Real Academia de Jurisprudencia y Legislación, Vocal de la Comisión compiladora del Derecho Civil Especial de Cataluña, Presidente Honorario de la Academia de Jurisprudencia y Legislación de Barcelona y Decano Honorario del Colegio Notarial de Barcelona. Su bibliografía es muy extensa, destacando sus estudios de Derecho Hipotecario, Estudios de Derecho Privado y los Estudios de Derecho Civil especial de Cataluña libro póstumo en el año 1983 por la editorial Bosch. 
a un modo de concebir y vivir el derecho desde la orientación constante de la justicia $^{38}$. El famoso jurista de Tárrega consigue dar el salto desde la jurisprudencia de conceptos a una ciencia jurídica abierta a la vitalidad y a la tradición negocial del pueblo. Es decir, comienza a vislumbrar los vacíos o lagunas del conceptualismo dogmático y trata de colmarlos mediante el estudio de la realidad empírica, lo que le conduce a distinguir y subdistinguir exhaustivamente la variada tipología de las relaciones jurídicas ${ }^{39}$.

Ahora bien, este derecho institucional no se crea, sino que se descubre en la realidad viva de cada pueblo, por ello la historia del derecho (experiencia vertical) y el derecho comparado (experiencia horizontal) son sus principales fuentes del conocimiento $^{40}$. Roca Sastre asume una tesis característica del pensamiento civilista de Bonfante, quien afirmaba que una institución puede tener una funcionalidad diferente, aún cuando conserve su estructura, en función de las exigencias históricas del momento ${ }^{41}$. Ramón María posee una visión naturalista y evolutiva del concepto de institución jurídica próxima a este historicismo, pero va más allá $^{42}$. Además, siente la necesidad de fundamentar positivamente la vigencia de este derecho institucional y, con esta intención, lo subsume dentro de la apelación a los principios generales del derecho en el artículo 1.4 del Código Civil ${ }^{43}$.

38 VAllet de Goytisolo, J., «Ramón Roca Sastre», op. cit., p. 613. «Roca Sastre ha efectuado en este siglo algo semejante, a lo expuesto, con respecto a la dogmática, conceptualista que nos llegaba en su época de estudiante. Supo despojarla de su positivismo genuino y de la rigidez de su método de inversión, para transformarla en lo que él denomina derecho institucional, caracterizándolo porque sus figuras son forjadas en la realidad, y requiriendo la adopción de las más convenientes, según criterios de adecuación histórica y local, para el bien común y, en definitiva, a la justicia».

39 Destacan especialmente en este sentido los once volúmenes de su magna obra Derecho bipotecario (reeditados por la editorial Bosch, Barcelona, 2009). Semejante empresa, por su magnitud, acometió Vallet con los Estudios de Derecho Sucesorio (Montecorvo, Madrid, 1980-1983).

40 Roca SaStre, R., «Prólogo», op. cit., p. 14.

41 Bonfante, P., Scritti giuridici varii, Unione Tipografia, Torino, 1916, p. 129.

42 Roca SASTRE, R., «Prólogo», op. cit., p. 14. Casals Colldecarrera ya había destacado la influencia de Bonfante en la metodología de Roca Sastre, Vid., Casals Colldecarrera, M., «Metodología de la aplicación del derecho», Discurso leído en la Real Academia de Jurisprudencia y Legislación el 28 noviembre de 1983 en Madrid.

43 Roca SASTRE, R., «Crítica institucional...», op. cit., p. 515. «De este modo, los principios generales del Derecho, de que habla el artículo 6 del Código vigente, serán los principios institucionales del sistema elegido, pues hay que tener en cuenta que el articulado de un Código, por completo que sea, no llega a agotar toda la materia a normar. Y así, en la aplicación analógica de la ley positiva y al tratar de llenar las lagunas fatalmente existentes en los Códigos, los principios inspiradores de la institución constituirán una abundante cantera de donde el juzgador sacará los materiales necesarios para integrar la norma legal insuficiente. Entonces será cuando el llamado Derecho institucional aparecerá con todo su valor». 
El juzgador hallará este derecho institucional en las propias leyes y costumbres del país. Es en las normas donde el intérprete descubrirá la lógica institucional que le permitirá integrar las lagunas del ordenamiento jurídico y, a falta de mejor ubicación legal, encontrará en la llamada a los principios generales del derecho la vía de acceso al denominado derecho institucional ${ }^{44}$. Como ejemplo de este modo intelectual de proceder se podría citar su estudio acerca del enriquecimiento injusto. Tras concluir la inadmisibilidad del negocio jurídico abstracto en nuestro Código Civil, Roca Sastre comienza a perfilar los rasgos de esta institución jurídica en la historia del derecho español y acaba por afirmar que se trata de una institución que engloba una pluralidad de situaciones dominadas por el principio «nadie debe enriquecerse con el perjuicio de otro ${ }^{45}$.

Ya en 1940, Roca Sastre demostraba el vértigo que sentía al abandonar los linderos del ordenamiento jurídico y, por ello, fundamenta empíricamente el derecho institucional en la exhuberancia de fórmulas e instituciones vividas a través de la Historia y la positividad del derecho ${ }^{46}$. Esto explica su reticencia al derecho natural y que suela sustituir el sustantivo «justicia» por el compuesto «lógica institucional». Ahora bien, cuando indagamos en el sentido de esta lógica acabamos descubriendo una justicia acorde con la naturaleza de la $\operatorname{cosa}^{47}$. En este sentido, el venerado jurista escribe: «Ante un interés el Derecho puede ofrecer para su amparo o protección diversas fórmulas, figuras

44 RoCa SASTRE, R., «Prólogo», op. cit., p. 16. «La jurisprudencia solo ha de ser fundamentalmente una formal expresión de las normas adecuadas a las que responde el tipo de figura o institución jurídica adoptada por el país, bien por medio de sus órganos legislativos, bien por el vigor de la costumbre».

45 Roca Sastre, R. y Puig Brutau, J., Estudios de derecho privado, Aranzadi-Thomson Reuters, Navarra, 2009, pp. 559-598. Roca Sastre concluye que el enriquecimiento injusto no se trata de una colisión entre el ius strictum y el ius aequum, sencillamente por la razón de que el negocio jurídico abstracto no existe en nuestro derecho civil. Al contrario, se trata de una institución jurídica que encuentra su arraigo histórico procesal en la actio verso in rem y su principio informador es «nadie debe enriquecerse en perjuicio de otro».

46 Roca SASTRE, R., «Crítica institucional...», op. cit., p. 497. «Esta demostración empírica del Derecho institucional es preferible, al menos de momento, a su demostración filosófica. En este último aspecto, baste decir que dicha visión institucional del Derecho se halla fuera de la órbita del llamado Derecho natural, tanto en su noción clásica (de contenido fijo e inmutable) como en su noción stammleriana (de contenido variable). Pero, con todo, funciona en él cierto logicismo iusnaturalista, pues el estilo dominante en cada construcción jurídica impone, en sus consecuencias, la rigidez de una verdadera lógica institucional».

47 Vallet de GoYtisolo, J., «La interpretación según Ramón María Roca Sastre», Revista Crítica de Derecho Inmobiliario, año LXXV, n. 651 (1999), p. 483. 
e instituciones jurídicas, de las que será elegida la que mejor se adapte al modo de ser, precedentes históricos y demás circunstancias del país respectivo ${ }^{48}$ ».

La noción de «derecho institucional» de Ramón Roca Sastre le permite superar los rígidos márgenes del conceptualismo dogmático y orillar un nuevo horizonte para la ciencia jurídica española, un método empírico y vitalista que observa las instituciones como productos históricos del devenir jurídico del pueblo. Las instituciones son reconocidas en su dimensión histórica y positiva como portadoras de un orden propio (lógica institucional), que se impone a las formas conceptuales y construcciones dogmáticas ${ }^{49}$. Roca rehúsa deliberadamente del intento de fundamentar filosóficamente su posición metodológica, si bien rechaza expresamente el influjo de la escuela histórica, del positivismo y del derecho natural moderno ${ }^{50}$.

Vallet, quien se confiesa discípulo y admirador de la obra de Roca Sastre $^{51}$, cree que el método de su maestro es el seguido por la escuela jurídica catalana a lo largo de los siglos de la historia de España. Un método realista que halla el contenido natural de justicia de los negocios e instituciones jurídicas en la realidad viva del pueblo, en virtud del peculiar seny natural y el respeto a las tradiciones, tan propio de la cultura catalana ${ }^{52}$. En suma, Vallet opina que el método de Roca Sastre no puede ser otro que el mismo realismo clásico, al que se adscribe el jurista de Barcelona como discípulo ${ }^{53}$. Además, el genial

48 Roca Sastre, R., «Prólogo», op. cit., p. 13.

49 Vallet De GoYTisolo, J., Reflexions sobre Catalunya. Relligament, interacció i dialéctica en la seva bistoria i el seu dret, Marcial Pons, Madrid, 2007, pp. 261.

50 RoCa SASTRE, R., «Crítica institucional...», op. cit., p. 497.

51 Vallet DE GoYTisolo, J., «Ramón Roca Sastre», op. cit., p. 617.

52 Vallet de Goytisolo, J., «Cotejo con la escuela histórica de Savigny», Revista furídica de Catalunya, año LXXVIII, n. ${ }^{\circ} 4$ (1979), pp. 806-819. Vid., ID., «Martí I Miralles al reencuentro del derecho catalán», Revista furídica de Catalunya, año C, n. 3 (2001), p. 722. Vallet considera que Martí I Miralles buscó los principios ético-naturales en la tradición histórica y esta enseñanza fue transmitida a Roca Sastre.

53 VALleT DE GoYTiSOlo, J., «La interpretación según...», op. cit., p. 486. «Sin embargo, su formación en el agro y el sentido práctico del derecho catalán le habían dotado de un claro realismo jurídico, no en el sentido del legal realista angloamericano ni del denominado realismo escandinavo, sino en el que tenía el derecho romano clásico y la tradición del ius commune en la línea del mos italicus, método que se venía viviendo intensamente en el derecho catalán». Una exposición más detallada de la vinculación de Roca Sastre con el realismo característico de la escuela jurídica catalana, la ofreció Vallet el 17 de octubre de 2003 en la Universidad de Cervera, concretamente, en los cursos organizados por la Fundación Roca Sastre «II Curs de Dret Civil». Vid., VAllet DE GOYTISOlo, J (inédito), Roca Sastre i l'escola jurídica catalana. El seu pensament juridic. (Una copia de los escritos preparados para estas lecciones me fue generosamente entregada por el autor). 
civilista de Tárrega supo captar la función que cumplen los juristas prácticos, especialmente el notario, en el alumbramiento de este derecho institucional ${ }^{54}$.

En este sentido, se puede adelantar que poca diferencia sustancial existe entre la idea de «derecho institucional» de Roca Sastre y la visión institucional del Sistema en Vallet. Más bien, podríamos decir que la reflexión de este último acerca de la institución jurídica es heredera de la idea de «derecho institucional» de Roca. Ahora bien, Juan Vallet no se limita a recoger el testigo, sino que profundiza en las reflexiones del maestro y se aventura allá donde éste quiso detenerse. Siendo así, Vallet acometerá el desafío de fundamentar filosóficamente este derecho institucional y, desde ahí, metódicamente procederá a una explicación omnicomprensiva del Derecho.

\section{VALLET DE GOYTISOLO Y EL «DERECHO INSTITUCIONAL» O CÓMO LA PRAXIS JURÍDICA CONSTRUYE PROGRESIVAMENTE LA CIENCIA}

Vallet de Goytisolo es, ante todo, un jurista práctico que a lo largo de su ejercicio profesional va introduciéndose progresivamente, primero, en la dogmática civilista mediante sus numerosos estudios sobre sucesiones, y, con posterioridad, en la filosofía jurídica ${ }^{55}$. Quiere esto decir que recorre el camino inverso a Roca Sastre, maestro que le devolvió al predio de los juristas y

54 Roca SASTRE, R., «La necesidad de diferenciar lo rural y lo urbano en el derecho sucesorio», Anales de la Academia Matritense del Notariado, Madrid (1945), pp. 331-377. «Donde no llegue, o no deba llegar la presión del legislador, debe llegar el Notario, o sea el consejero nato de los otorgantes».

55 Juan Berchmans Vallet de Goytisolo (1917-2011) nació en Barcelona y se graduó en Derecho por la Universidad de Barcelona en 1939. El 24 de noviembre de 1942, con veinticinco años de edad, consigue su primer destino como notario en Torroella de Montgrí. En 1944 tomaría posesión de la notaría de Malgrat, dos años después en 1946 tomaría la notaría de Arucas, en 1947 ganaría por concurso la de Logroño y, finalmente, en 1949 por oposición directa ganaría su notaría en Madrid, que ejerció hasta su jubilación en 1987. Su carrera investigadora se inicia en 1946 (29 años de edad) con un estudio sobre las compras con pacto de sobrevivencia, su primer libro será publicado en 1951 a la edad de 34 años y tiene como temática la hipoteca del derecho arrendaticio, en 1963 con 46 años accede a la Real Academia de Jurisprudencia y Legislación con la ponencia titulada «Perspectiva histórica de las cautelas testamentarias de opción compensatoria de la legítima». Su producción es de tal extensión que sería excesivo referirse a todas sus obras en esta breve nota, sirva como muestra de su peculiar disciplina investigadora el calificativo «trapero del tiempo» con el que Federico de Castro quiso retratar su modo de trabajar, pues siempre encontraba el tiempo necesario para el estudio y la escritura. (Este calificativo lo conozco por las palabras de su hijo Javier Vallet pronunciadas el 30 mayo 2012 en la presentación del libro conmemorativo Artícles seleccionats. Col. Premi Puig Saleillas, Marcial Pons, Madrid, 2011). 
lo apartó definitivamente de la disciplina castrense ${ }^{56}$. Hay un suceso vital en los inicios de la carrera profesional de Vallet que le marcará definitivamente: recientemente salido de las oposiciones a notarias había conseguido la plaza en una notaria pequeña de Torroella de Montgrí y cuando comenzó a redactar sus primeras escrituras públicas lo hizo con arreglo a los conocimientos teóricos que había aprendido. El registrador de la propiedad Jaime Bossacoma le hizo ver la conveniencia de introducir los pactos sucesorios y las cláusulas negociales comunes en la región, aun cuando las partes no se hubieran pronunciado ${ }^{57}$. A partir de este momento, comenzó Vallet a descubrir cómo el derecho va íntimamente ligado a la historia vital de las regiones y cómo se manifiesta particularmente en concretos tipos contractuales, pactos sucesorios y cláusulas negociales que modifican, adaptan o extienden el contenido de los tipos generales a los rasgos peculiares de las regiones. Expresamente, escribe al respecto Vallet: «La pauta ética y el respeto a los usos vividos para configurar la voluntad de los otorgantes, siguiendo los cauces que dejan libres las normas imperativas y prohibitivas, creo deben constituir la pauta general orientadora del notario» ${ }^{58}$.

De acuerdo con el planteamiento metodológico de Juan Vallet, la variada y multiforme vida negocial del pueblo es el resultado de la labor de concreción del derecho realizada por los juristas prácticos, quienes con su labor alumbran los principios de justicia que luego serán desarrollados por la ciencia jurídica y los juristas teóricos ${ }^{59}$. Es una de las principales discrepancias entre Vallet y su amigo Elías de Tejada, que quedó reflejada con ocasión de los estudios sobre El título preliminar del Código Civillo ${ }^{6}$. Esta tesis de Vallet encuentra su origen en la tradición jurídica catalana, de la que se siente parte, y lejos de buscar el

56 Vallet de Goytisolo, J., Apuntes de Derecho sucesorio, Instituto Nacional de Estudios Jurídicos, Madrid, 1955. En la dedicatoria encontramos: «A Ramón M. ${ }^{a}$ Roca Sastre, que en los primeros años de nuestra postguerra volvió a despertar en mí la afición al Derecho, que se me había adormecido con el olor de la pólvora y el ruido de las explosiones».

57 ID., «La determinación notarial del derecho», Anales de la Academia Matritense del Notariado, Madrid, 1995, p. 508.

58 Ibid., p. 509.

59 ID., Metodología de las leyes, Editoriales de Derecho Reunidas, Madrid, 1991, p. 354. «Y esa praxis -propia de los jurisprudentes no de los filósofos- ayuda tanto a la determinación y concreción de los primeros principios de la razón práctica, como al alumbramiento de los principios generales de derecho de cada una de las ramas del derecho y sus instituciones».

60 Elías De Tejada, F., «Los principios generales del Derecho en el art. 1. ${ }^{\circ}$ del Código civil reformado en 1973», Estudios tras la reforma del Título Preliminar del Código Civil, vol. I, Edersa, Madrid, 1977, p. 87. 
derecho en las obras eruditas y en los códigos lo intenta hallar en la práctica de los juristas y la determinación negocial del derecho ${ }^{61}$.

Estas construcciones vitalistas de los juristas -para las que Vallet reserva el calificativo de instituciones- son posteriormente trasladadas al ámbito de la ciencia del Derecho con el objetivo de su clasificación y categorización. Gracias a esta labor de los juristas las instituciones jurídicas van progresivamente perfilándose, mejorando su adaptación a la realidad jurídica ${ }^{62}$. En consecuencia, defiende Vallet una metodología de la ciencia jurídica que se sirve de la abstracción integrativa ${ }^{63}$ (no sustractiva) y que encuentra como mejor herramienta del método el universal aristotélico ${ }^{64}$.

\section{Clasificación de las INSTITUCIONES JURÍDiCAS EN VALLET DE GOYTISOLO}

Nuestro autor realiza una clasificación de las instituciones jurídicas atendiendo a su naturaleza, del siguiente modo:

- Institución jurídica como persona e institución jurídica como figura. Vallet distingue entre institución orgánica corporativa (institución persona) e institución figura estructural.

Es una distinción clásica en la doctrina, ya Hauriou expresaba: «institución es una idea de obra o empresa que se realiza y dura jurídicamente en un medio social; para la realización de esta idea, se organiza un poder, se le procura los órganos necesarios y, por otra parte, entre los miembros del grupo social interesado en la realización de una idea, se producen manifestaciones de comunión dirigidas por órganos de poder y reglamentadas por procedimientos ${ }^{65}$. En Hauriou, la ideaacción es la causa determinante de la unión de voluntades subjetivas.

61 Vallet de Goytisolo, J., «La esencia y principios del derecho civil foral», Revista jurídica de Cataluña, vol. 69, n. ${ }^{\circ} 1$ (1970), pp. 378-380.

62 ID., «Las instituciones jurídicas: definición, análisis, tipificación, clasificaciones y funciones», Anuario de Derecho Civil, vol. 55, n. 1 (2002), pp. 25-28.

63 Ibid., p. 19.

64 ID., «Conceptos y tipos. Razonamiento conceptual y razonamientos tipológicos», Anales de la Real Academia de Furisprudencia y Legislación, n. ${ }^{\circ} 34$ (2003), p. 15-30.

65 Hauriou, M., La Teoría de la Institución y de la Fundación (ensayo de vitalismo social), Abeledo Perrot, Buenos Aires, 1968, p. 31. 
Muchos autores han seguido la estela de $\mathrm{Hauriou}^{66} \mathrm{y}$ han tratado de buscar una concepción institucionalista que sirva para comprender tanto la institución persona como el mismo orden jurídico, así ocurre en Renard, Delos y Ruiz Giménez ${ }^{67}$. Igualmente, en Alemania, desde las filas del idealismo objetivo encontramos a Larenz y su idea de las instituciones como manifestaciones de la acción del espíritu del pueblo (idea) sobre la vida humana (materia). En definitiva, estos autores persiguen construir una Teoría del Derecho a partir de la noción de institución jurídica y, por ello, buscan una noción que les sirva para dar cuenta de una teoría general del acto jurídico y del derecho positivo ${ }^{68}$. En definitiva, todos ellos tratan de buscar el fundamento objetivo del fenómeno jurídico y, por ello, acaban por desarrollar una ontología jurídica.

Esta confusión entre institución persona e institución figura es especialmente notoria en el caso de Larenz, pues, en tanto idealista, la materia sucumbe ante la fuerza de la idea y baste como prueba que en él la última ratio de toda materia jurídica (individual y social) es el espíritu del pueblo en un proceso de realización constante ${ }^{69}$. El realismo metódico de Vallet le conduce por derroteros distintos al idealismo objetivo, ya que él sigue una metodología subjecta materia. Es decir, cada materia particular, cada cosa o acontecimiento, posee su propio orden y determina la construcción científica ${ }^{70}$.

66 Esta idea será una constante en sus discípulos, Vid., RENARD, G., La theorie de l'institution..., op. cit., p. 95. «La institución es la comunión de hombres dentro de una idea (la traducción es mía)».

67 Ruzz Giménez, J., La concepción institucional del Derecho, Instituto de Estudios Políticos, Madrid, 1944, pp. 423-446. Siguiendo a Renard, Ruiz Giménez escribe su síntesis acerca de la idea de «justicia institucional», que sería el orden de la convivencia humana en virtud del cual se subordinan los intereses privados a los supremos intereses de la comunidad. Un criterio de justicia «social» bajo cuya dirección se hace posible la coordinación de la justicia conmutativa y la distributiva; en otras palabras, el bien común.

68 Ibid., p. 103. Escribe Ruiz Giménez siguiendo a Delos: «La justicia del contrato se realiza en la entraña del objeto como en la entraña del objeto radica la justicia de la Ley y la legitimidad de la fundación».

69 LARENZ, K., La filosofía contemporánea..., op. cit., pp. 283-284. «El pensamiento de un orden concreto tiene que fundamentarse en una teoría del espíritu del pueblo como metafísica del espíritu concreto, que a su vez sólo puede ser desarrollada ulteriormente en una conexión con la ciencia jurídica».

70 Vallet de Goytisolo, J., «Las instituciones jurídicas...», op. cit., pp. 14-20. Vallet sostiene una posición muy similar a la doctrina de las unidades plurales de Santo Tomás, como veremos en las siguientes palabras: «Yo digo que la vida está inseparablemente en el todo y en cada una 
En consecuencia, conviene distinguir las instituciones entendidas como realidad corporativa de las instituciones entendidas como figuras jurídicas, estas últimas genéricamente son entendidas, en palabras de Vallet, como «moldes flexibles, con los que los juristas en contacto con la realidad viva, definimos las realidades jurídicas que observamos» ${ }^{71}$.

En atención a su funcionalidad, Vallet divide las instituciones jurídicas en los siguientes tipos:

- Institución jurídica cauce ${ }^{72}$. Como su propio nombre indica, éstas son el cauce jurídico para dar cumplimiento a la voluntad de los sujetos, o bien configuran o completan esta voluntad partiendo de lo objetivamente presumible. Es decir, son instituciones cuya funcionalidad es conducir las relaciones negociales hacia su fin natural: la realización de la voluntad de las partes, ayudando a desarrollar el contenido de la relación negocial. Ejemplos de este tipo de instituciones serían las cautelas que persiguen reforzar el cumplimiento de las obligaciones o excluir la aplicación de determinadas normativas, como por ejemplo el pactum de non petendo, la renuntiatio, la compraventa con pacto de sobrevivencia, el legado de usufructo universal a favor del cónyuge viudo o la opción compensatoria de la legítima, entre otras $^{73}$.

de sus partes con tal de que éstas no se separen del todo; pues, si bien se contemplan como partes estructurales suyas, se hallan integradas funcionalmente de modo inseparable en el todo (que es algo vivo y no un cadáver al que se le hace la autopsia y despedaza. Ciertamente, todas las instituciones se integran en el sistema de cada derecho vivo: estructuralmente -que el modo que aquí las examinamos- y funcionalmente, en su dinámica, y ni de un modo ni de otro pueden separarse de él, pero sí cabe considerarlas individualmente. Pero, lo mismo que ocurre con el derecho, sucede con cada una de sus instituciones, que pueden ser observadas, integradas por todas las partes que constituyen su estructura, es decir, en su composición» (p. 20).

71 Vallet de Goytisolo, J., Panorama del Derecho de sucesiones, vol. I, Civitas, Madrid, 1982, p. 15.

72 Ibid., pp. 149 y ss. En esta obra establece por primera vez Vallet la distinción entre instituciones cauce e instituciones dique. Con posterioridad, en el año 2002 con motivo de un estudio sobre la institución publicado en el Anuario de Derecho Civil añadiría las instituciones formales de publicidad y procedimentales.

73 ID., Metodología de la ciencia expositiva y explicativa del Derecho. Elaboración sistemática, tomo II, vol. II, Fundación Cultural del Notariado, Madrid, 2003, p. 1256. 
- Institución jurídica límite o dique $e^{74}$. Estas instituciones consisten en barreras introducidas por las leyes o las costumbres al desarrollo de las instituciones cauce. Según su naturaleza se pueden subdividir en reconductoras, impeditivas, disuasorias y penales ${ }^{75}$ :

a) Las reconductivas delimitan el desarrollo de las instituciones cauce dentro de límites concretos. Un ejemplo de esta institución dique es la legítima legal o legítima estricta.

b) Las impeditivas cierran el paso a determinadas instituciones sociales dejándolas en el ámbito de la mera facticidad, como es el caso de la unión de hecho o la posesión en precario.

c) Las disuasorias establecen trabas y dificultades con la finalidad de disuadir a los particulares sobre la conveniencia de determinadas prácticas negociales. El ejemplo característico de institución disuasoria serían los gravámenes fiscales o trabas administrativas.

d) Las penales establecen sanciones y su finalidad no es otra que prohibir o castigar determinadas prácticas negociales. Como ejemplo de estas instituciones limitativas tenemos prohibiciones legales de todo tipo e instituciones como el enriquecimiento injusto.

- Instituciones jurídicas formales, de publicidad y procedimentales $^{76}$. Se trata de instituciones que tienen como función establecer un modo concreto para la existencia u operatividad de la práctica negocial. Se dividen en instituciones formales, de publicidad y procedimentales ${ }^{77}$ :

a) Las instituciones formales tienen por objeto exteriorizar, dar seguridad y fijeza a las instituciones sustantivas que la requieren. Encontraríamos entre ellas formas obligatorias y formas libres, formas de ser y formas de valer, así como formas litúrgicas y formas funcionaristas.

b) Las instituciones de publicidad tienen como función dotar de publicidad a determinadas relaciones jurídicas, situaciones y negocios jurídicos para que sean conocidos por terceros. Hoy predomina el sistema de registros públicos.

74 Vallet de Goytisolo, J., Panorama del Derecho..., op. cit., pp. 437 y ss.

75 ID., «Las instituciones jurídicas...», op. cit., p. 39.

76 Ibid., pp. 41-44. Vallet individualiza este tipo de instituciones por primera vez en 2002 en el Anuario de Derecho Civil y, con posterioridad, en su obra Metodología de la ciencia expositiva y explicativa del Derecho (2003).

77 ID., Metodología de la Ciencia..., tomo II, vol. II, op. cit., pp. 1261-1265. 
c) Las instituciones procedimentales tienen por objeto dotar de operatividad y seguridad a los procesos que son exigidos para el correcto funcionamiento de la relación jurídica o para que ésta alcance su finalidad propia. Un ejemplo muy actual de este tipo de institución podría ser la mediación intra y extrajudicial, familiar, civil y mercantil. Ahora bien, también, entrarían aquí el concurso de acreedores, la reconstrucción de protocolos notariales, la ejecución extrajudicial, la declaración ab intestato, etc.

\section{LA INSTITUCIÓN JURÍDICA EN LA METODOLOGÍA DE LA DETERMINACIÓN DEL DERECHO}

Vallet tiene una visión tripartita de la metodología jurídica. Muy sintéticamente diré que, de acuerdo con el gran jurisconsulto español, una metodología completa debe abarcar: a) el objeto de la ciencia, sus causas y principios; b) la finalidad que se persigue; c) el camino que debe recorrerse, cómo acometerse y concluirse; d) las cualidades y preparación que el sujeto requiere; e) los elementos instrumentales que deben utilizarse; y f) las técnicas precisas para utilizar el instrumental del que se dispone ${ }^{78}$. Ahora bien, como sea que la experiencia acerca del derecho no es la misma para el jurista práctico, el teórico del derecho o el propio legislador, esta situación exige que se desarrollen tres metodologías complementarias: la metodología de la determinación del derecho, la metodología de las leyes y la metodología de la ciencia expositiva y explicativa del derecho. La primera se ocupa de la determinación de lo que es justo en cada caso particular, la metodología de las leyes busca ofrecer al legislador unas pautas racionales para dictar leyes adecuadas a la naturaleza de las cosas y a la naturaleza de cada comunidad política y, finalmente, la metodología de la ciencia expositiva y explicativa del derecho intenta proporcionar al jurista los conocimientos científicos necesarios para su praxis. Entre ellas, la metodología de la determinación del derecho ocupa un lugar de honor, porque el objeto del derecho, su finalidad ínsita, es el hallazgo de lo que es justo en las relaciones humanas ${ }^{79}$.

78 Vallet de Goytisolo, J., Manuales de metodología jurídica, vol. I, Fundación Cultural del Notariado, Madrid, 2004, p. 20.

79 ID., Metodología de la determinación del derecho, tomo I, Fundación Ramón Arecces, Madrid, 1994, p. 6. Vallet recoge de este modo el testigo de Castán Tobeñas, quien había diferenciado tres 
Desde la perspectiva de la determinación del derecho, la institución jurídica juega un papel fundamental en la práctica negocial de los particulares, en la actividad judicial y en la correcta comprensión de la analogía jurídica, lo que veremos a continuación. También, analizaremos la importancia de la institución jurídica en la práctica legislativa, pero reservaremos un lugar propio para el análisis de la funcionalidad de la institución en la metodología de la ciencia expositiva y explicativa del derecho.

- La determinación de la res iusta negocial. Vallet considera las relaciones negociales de los particulares en el ámbito del dikaion phisikon, esto es, lo justo natural e indiferente al derecho positivo ${ }^{80}$. Corresponde a los particulares la libre determinación de lo justo en sus relaciones y, para ello, cuentan con la ayuda de los juristas prácticos, quienes prudencialmente orientarán la voluntad e intereses particulares dentro de los fines generales del Derecho ${ }^{81}$. Esta orientación se efectúa bien desaconsejando determinadas fórmulas o cláusulas negociales, o, por lo general, aconsejando la mejor fórmula para la realización de sus intereses y completando su voluntad en aquellos extremos no previstos inicialmente por las partes ${ }^{82}$. Vallet considera que el mejor ejemplo de esta praxis negocial lo constituye la figura del notario y su actividad consultiva $^{83}$.

- La institución jurídica en la determinación judicial del derecho. La institución jurídica se ofrece al juez como un compuesto fáctico y valorativo que sirve como herramienta para la comprensión de la variada realidad jurídica, permitiendo identificar, calificar y encauzar las múltiples relaciones negociales ${ }^{84}$. En este sentido, creo que es posible afir-

modos de elaboración del derecho: la elaboración creadora, la elaboración reconstructiva científica y la elaboración reconstructiva práctica. Vid., CASTÁN TOBEÑAs, J., Teoría de la aplicación e investigación del derecho, Reus, Madrid, 2005, p. 42.

80 VAlLET De GoYTISOlo, J., «La determinación notarial...», op. cit., pp. 470-473. Considera Vallet que no existe negocio jurídico, será nulo, si no existe consentimiento, objeto o causa verdadera y lícita.

81 ID., Metodología de la Ciencia..., tomo II, vol. II, op. cit., p. 1268.

82 ID., «La determinación notarial...», op. cit., pp. 489-496.

$83 \mathrm{Ibid}$., p. 506. Al desarrollar la determinación notarial del derecho vuelve Vallet a continuar el camino trazado por Castán. Vid., CASTÁN TobeÑas, J., Función notarial y elaboración notarial del derecho, Reus, Madrid, 1946, pp. 93-137.

84 Vallet de GoyTisolo, J., Metodología de la Ciencia..., tomo II, vol. II, op. cit., p. 1275. «Si para inteligir un texto es preciso referir sus palabras a la 'cosa del texto', esa cosa de la cual habla el 
mar que para Vallet la institución jurídica constituirá la herramienta principal para la interpretación correctora del juez, corrigiendo así los vacíos, silencios, ambigüedades y contradicciones de los textos contractuales o de los textos legales positivos ${ }^{85}$.

- Institución jurídica y analogía. La característica propia de la institución jurídica es ser una «unidad de sentido» entre la multiforme realidad negocial, es decir, una misma razón de orden compartida entre varias relaciones o hechos jurídicos, por lo cual parece necesario que la institución jurídica ocupe un lugar de primacía dentro de la teoría analógica del Derecho. De acuerdo con Vallet, será la institución jurídica en tanto elemento de orden o razón común entre diversas relaciones lo que permitirá predicar la corrección o incorrección de la interpretación analógica, es decir, será la institución jurídica la que permitirá identificar ese «aire de familia» entre los nuevos y atípicos sucesos de la vida real y los hechos o relaciones ya categorizados y conceptualizados por la ciencia jurídica y las leyes ${ }^{86}$.

- La institución jurídica en la legislación. La institución también es útil a la praxis legislativa en la medida que un adecuado conocimiento de las instituciones es clave para una buena legislación ${ }^{87}$. En este sentido, Juan Vallet observa la institución jurídica como una «preforma ${ }^{88}$ del derecho legislado, que determina positivamente el contenido de las leyes. Cuestión aparte es el hecho de que el jurista de Barcelona conciba

texto, si se regula en una norma de derecho, se enmarca en instituciones tipificadas, que sirven para encuadrar los hechos a que la interpretación se dirige, a fin de clasificarlos y estimarlos jurídicamente después».

85 Entiéndase por interpretación correctora la señalada por: CASTÁn TOBEÑas, J., Teoría de la aplicación..., op. cit., pp. 269-270.

86 VAllet De GoYTisolo, J., «La interpretación según el título preliminar del Código Civil», Discurso leído el día 18 de noviembre de 1996 en la Sesión Inaugural del Curso Académico 1996-1997 de la Real Academia de Jurisprudencia y Legislación, pp. 97-100.

87 ID., Metodología de la Ciencia..., tomo II, vol. II, op. cit., p. 1289. «Siendo así, las instituciones son, ante todo, modelos para el legislador y la fundamental guía de los intérpretes para intelegir las normas legales y explicar jurídicamente los bechos».

88 Henkel, H., Introducción a la Filosofía del derecho, Taurus, Madrid, 1968, p. 445. «De esta forma, entre el acervo institucional de la realidad social y el derecho positivo se mueve una ininterrumpida corriente de integración que lleva a la juridificación y que proporciona al derecho nuevos sectores y nueva vida. Donde más clara es la transformación en la forma jurídica es en la recepción de productos, preformas e inicios institucionales mediante el acto legislador; pero también se lleva a cabo en la paulatina formación de una jurisprudencia constante que obtiene normas de derecho judicial de las instancias institucionales de la vida social». 
un orden institucional orgánico, fundado en los cuerpos intermedios (instituciones-persona) como el mejor clima socio-político posible para una óptima legislación ${ }^{89}$.

\section{LA INSTITUCIÓN JURÍDICA EN LA METODOLOGÍA DE LA CIENCIA EXPOSITIVA Y EXPLICATIVA DEL DERECHO}

El Sistema jurídico es definido por Vallet como «el funcionamiento real, ordenado en instituciones de conformidad a la naturaleza de las cosas, de un conjunto de principios, leyes, reglas y pautas de valor, orientado a la realización y concreción, en los hechos, de lo que es justo y equitativo en concreto y en acto $^{90} \gg$. A la luz de esta definición ya se puede observar el lugar preponderante de la institución jurídica en su idea de Sistema y que son las instituciones las unidades de sentido (principios, leyes, reglas y pautas de valor) que orientan la realización de la justicia. El Sistema o «logos» de la realidad jurídica es el resultado de un entramado de instituciones alumbrado por la práctica jurídica y ordenado por la labor de los juristas teóricos, que tiene como idea aglutinante o finalidad la realización de lo justo en el caso concreto.

El Sistema puede ser observado estructural o funcionalmente. La dimensión estructural del Sistema nos ayuda a comprender la anatomía del organismo jurídico, sus diferentes elementos, órganos, tejidos, etc. La dimensión funcional del Sistema nos ayuda a comprender la misión que desempeñan los diferentes elementos, la funcionalidad que tienen dentro del conjunto del organismo ${ }^{91}$. La función que cumplen las instituciones jurídicas dentro de la dinámica del derecho la hemos visto con anterioridad al ocuparnos de la metodología de la determinación del derecho, pues no se puede olvidar que la concreción de lo que es justo en cada caso concreto es el objeto último de toda operación jurídica. La misma idea de derecho institucional revela una concepción vitalista del ordenamiento jurídico que

89 VAllet DE Goytisolo, J., «Constitución orgánica de la nación», Verbo, serie XIV, n. o 233-234 (1985), pp. 305-382.

90 ID., Metodología de la ciencia expositiva y explicativa del derecho, tomo II, vol. I, Fundación Cultural del Notariado, Madrid, 2002, p. 342.

91 ID., «Profundización en la sistemática metodológica de la ciencia expositiva y explicativa del derecho», Anales de la Real Academia de Furisprudencia y Legislación, n. 31 (2001), p. 126. 
está en un continuo proceso de expansión gracias a la labor de los juristas prácticos $^{92}$.

Ahora debe señalarse, en cambio, la importancia que tiene la institución jurídica como categoría estructural de la realidad jurídica, esto es, como figura que perfila y educa el razonamiento jurídico. Los científicos del Derecho han de recoger las instituciones nacidas de la práctica, exponerlas, clasificarlas, integrarlas dentro de su respectivo ámbito y delimitarlas respecto a otras figuras similares o divergentes. De ese modo alcanzamos el conocimiento de cómo están dispuestas las cosas jurídicas ${ }^{93}$. En estas breves líneas tenemos compendiada la vocación de la ciencia expositiva y explicativa del derecho, cuya finalidad es metabolizar científicamente las instituciones jurídicas elaboradas por los prácticos. Toda vez que la institución ha superado la retícula de los juristas teóricos, está lista como herramienta para la calificación jurídica de los hechos, para la integración de hechos y normas, para la extensión teleológica del contenido de las normas, para la corrección de los mandatos normativos, para la interpretación analógica y para la praxis prudencial legislativa ${ }^{94}$.

En virtud de esta concepción vitalista de la institución jurídica y del propio Sistema, consigue Vallet situarse en una dirección alternativa al Sistema de Savigny ${ }^{95}$. La diferencia que separa ambas concepciones se muestra en la labor

92 Esta es una idea fundamental para comprender la noción de institución jurídica en Vallet de Goytisolo, y hemos visto hasta qué punto es deudora de las enseñanzas de su maestro Roca Sastre. Vid., Vallet de GoyTisolo, J., Metodología de la Ciencia..., tomo II, vol. II, op. cit., p. 1302. «Por mi parte sigo con el criterio de optar por el sistema de instituciones, como cosas jurídicas elaboradas en la práctica jurídica, teniendo en cuenta que esas cosas jurídicas tienen insitos sus valores y, en cuanto son jurídicas, contienen un espíritu de justicia que las dota de su adecuada forma justa».

93 Vallet DE GoYTISOlo, J., «Las instituciones jurídicas...», op. cit., p. 27.

$94 \mathrm{Ibid}$., p. 47. «A su vez, los científicos del derecho, al retornar su mirada a esa labor práctica, asumen la tarea de definir esas instituciones, y deslindarlas y clasificarlas, primero, y la de exponerlas, explicarlas y estructurarlas, después. Así se trata de explicar funcionalmente el derecho tal como es en su estructura real, en la función teórica que la ciencia del derecho realiza con las instituciones. Finalmente, una vez afinadas éstas, se trata de explicar su configuración en tipos y series de tipos, que sirven de ayuda a la práctica legislativa para que ésta efectúe su formulación normativa, y a la práctica de la determinación del derecho para intelegir, integrar e interrelacionar estas normas en un sistema».

95 Vallet de Goytisolo, J., Metodología de la Ciencia expositiva y explicativa del derecho. La Ciencia del Derecho a lo largo de su Historia, tomo I, Fundación Cultural del Notariado, Madrid, 2000, p. 512. «Lo que le ocurre a Savigny, a mi entender, es que no va y vuelve de la contemplación del todo a la de una realidad singular, sino que se mueve mentalmente entre aquella contemplación total y la regla abstracta, formada mediante un concepto que, a su vez, es construido por una abstracción sustractiva al modo kantiano». En este sentido, debe señalarse que Vallet se sirve de 
que atribuye Vallet a los juristas prácticos y a los jueces en el alumbramiento de las instituciones jurídicas que, posteriormente, serán clasificadas y examinadas por la retícula de los juristas teóricos ${ }^{96}$. En cambio, para Savigny son los juristas teóricos los encargados de adaptar las normas legisladas a la vida real mediante el desarrollo de instituciones que, gracias a esta labor de teorización, se ofrecen como productos acabados a los juristas prácticos ${ }^{97}$. Precisamente, es esta peculiar afinidad que muestra el jurista alemán por un derecho erudito, propiedad de los juristas teóricos, lo que abre la senda del conceptualismo dogmático o Jurisprudencia de conceptos ${ }^{98}$. A juicio del jurista de Barcelona, Savigny olvidaba que son los prudentes y no los teóricos quienes guían al pueblo en sus relaciones jurídicas y contribuyen a que progresen, pues los juristas teóricos sienten una necesidad irreprimible de transformar sus conocimientos jurídicos en leyes y en códigos que encorsetan la espontaneidad del pueblo y el desarrollo paulatino de su derecho ${ }^{99}$. Más aún, concluye Vallet: «es de notar, de una parte, que la práctica jurídica no se reduce a la de los tribunales de justicia; y, de otra parte, que la labor de los juristas prácticos es fundamentalmente la de guiar el desenvolvimiento del derecho en la vida cotidiana. Ésta no es función directa de los juristas doctos a quienes sólo los prácticos pueden informarles de ella ${ }^{100}$.

En suma, la labor cotidiana de los juristas prácticos (abogados, notarios y jueces) permite la floración de instituciones enraizadas en la vida negocial del pueblo y nos muestra un derecho vitalista en un continuo proceso de forma-

la construcción sistémica de Savigny a «beneficio de inventario», es decir, recoge la concepción orgánica institucional del fundador de la Escuela histórica, pero desecha aquellas posiciones que lo acercan al normativismo o a un conceptualismo dogmático.

96 Vallet de Goytisolo, J., Estudios sobre Fuentes del Derecho y Método furídico, Montecorvo, Madrid, 1982, p. 930.

97 Savigny. F., Sistema del Derecho..., op. cit., p. 188. «El elemento sistemático tiene por objeto el lazo íntimo que une las instituciones y reglas del derecho en el seno de una vasta unidad. El legislador tenía ante sus ojos tanto este conjunto como los hechos históricos, y, por consiguiente, para apreciar por completo su pensamiento, es necesario que nos expliquemos claramente la acción ejercida por la ley sobre el sistema general del derecho y el lugar que aquella ocupa en el sistema».

98 LaREnZ, K., Metodología de la ciencia del derecho, Ariel, Barcelona, 1980, p. 35. «Lo que forma el sistema, por tanto, no es la conexión orgánica de los institutos, sino la conexión lógica de los conceptos (abstractos generales). Pero en esta conexión no se puede insertar posteriormente la contemplación total de un instituto jurídico».

99 Vallet de Goytisolo, J., «Los orígenes de la escuela histórica del derecho alemana y sus avatares», Anales de la Real Academia de Ciencias Morales y Políticas, n. ${ }^{\circ} 86$ (2009), p. 51.

100 Ibid., p. 52. 
ción, es decir, un Sistema de instituciones verdaderamente orgánico. Al contrario, el Sistema de Savigny se levanta sobre las raíces de la vida jurídica del pueblo para elevarse hacia un derecho legislado, patrimonio de la construcción científica de los juristas doctos, que acaba por ser una abstracción lógica y no una realidad orgánica. El denominado organicismo de Savigny sucumbe ante la sistematicidad lógica de los juristas doctos; pero no ocurre así en Vallet y su apreciada escuela jurídica catalana, quienes ven en los juristas prácticos los artífices de lo justo ${ }^{101}$.

\section{ConCLuSIONES}

1. ¿Las instituciones jurídicas como la propiedad o la sucesión intestada existen realmente o son simples categorías mentales sin entidad propia? En uno y otro caso cha de tener o no en cuenta el derecho estas formaciones considerándolas causa de las relaciones que regula? Y si lo hace ¿es por pura conveniencia teórica, por ficción técnica o por el reconocimiento de una base ontológica impostergable?

Hemos visto al inicio de este escrito que la respuesta será diferente dependiendo de nuestra posición filosófica y se adelantó que únicamente desde las premisas del realismo clásico se podría tener una visión completa de la institución jurídica. Toda vez que aceptamos que la razón, más allá de operar descriptivamente en el orden natural, es capaz de descubrir en el mismo prescripciones que se imponen a nuestro entendimiento, estamos volviendo al modo de razonar de la filosofía aristotélica.

En este sentido, la naturaleza de las cosas se revela como la categoría primera de una ontología general del cosmos que nos permite descubrir la existencia de un orden racional, en virtud del cual cada cosa tiene su posición y su destino natural en el mismo ${ }^{102}$. Vallet fundamenta filosóficamente la institución jurídica en la naturaleza de las cosas y el dikaion phisikon aristotélico.

\footnotetext{
101 Si se prefiere «sacerdotes de la justicia» como ya señalara Ulpiano en el Libro I del Digesto: «Cuius merito quis nos sacerdotes appellet: iustitiam namque colimus et boni et aequi notitiam profitemur, aequum ab iniquo separantes, licitum ab illicito discernentes, bonos non solum metu poenarum, verum etiam praemiorum quoque exhortatione efficere cupientes, veram nisi fallor philosophiam, non simulatam affectantes». Vid., Cuerpo del Derecho Civil Romano, Ed. bilingüe de I. L. García del Corral, Jaime Molina, Barcelona, 1889-1898.

102 Villey, M., Leçons d'histoire de la philosophie du droit, Dalloz, Paris, 2002, p. 29.
} 
Yo no niego esta fundamentación, pero añadiría la doctrina de las unidades plurales de Santo Tomás en el sentido señalado, es decir, entendiendo la institución como unidad de sentido. En consecuencia, la institución sí que tiene una entidad propia: es la «preforma» o «dato previo» del derecho legislado y del razonamiento jurídico, es una realidad viva en un continuo proceso de evolución en virtud de la constante actividad de los juristas y supone el reconocimiento de la base ontológica inherente al Derecho.

Cada institución jurídica se puede observar como un subsistema dentro del Sistema jurídico. La institución es un cauce de justicia y posee de suyo un orden criteriológico. De modo que cumple una triple función: a) facilita la comprensión de la realidad jurídica como instrumento de clasificación; b) orienta la práctica prudencial del derecho en tanto cauce natural de justicia; y c) supone un «dato previo a la norma», que el legislador no puede desconocer si no quiere caer en el absurdo.

Bajo esta premisa ontológica -lo justo se encuentra en las cosas ${ }^{103}-$ la interpretación del derecho no se trata ni de un juicio silogístico aplicativo de la norma legal, ni tampoco un acto creador del derecho, sino de un proceso de comprensión dirigido al hallazgo y determinación de lo que es justo en cada caso singular.

2. Vallet sobredimensiona la figura del jurista práctico y descuida la figura del juez y la autoridad pública. Los negocios jurídicos, aún cuando nunca lleguen a los tribunales, se construyen desde la premisa del conflicto y su posibilidad, por ello la actividad judicial y la jurisprudencia merecen una posición de predominio. Incluso, la actividad del notario se encuentra subordinada en algunos casos a la actividad del registrador público.

Lo que se intenta trasladar al lector es que el Derecho presenta un elemento de autoridad impreterible para su conocimiento, al igual que para su práctica. Vallet comenzó a corregir este descuido en sus últimas obras ${ }^{104}$, pero no llegó a explicar lo que, en mi opinión, es un axioma: la actividad de los juristas encuentra su alfa y omega en el conflicto de intereses o la posibilidad

${ }^{103}$ Santo Tomas De Aquino, Summa Theologica, $\mathrm{II}^{\mathrm{a}}-\mathrm{II}^{\mathfrak{x}}$, q. 77,2, resp., BAC, Madrid, 1993 , p. 436.

${ }^{104}$ Vallet de Goytisolo, J., «La función de juzgar y sus aportaciones al arte y a la ciencia del derecho», Anales de la Real Academia de furisprudencia y Legislación (2010), pp. 17-34; ID., «El razonamiento judicial», Anales de la Fundación Francisco Elías de Tejada, n. ${ }^{\circ} 15$ (2009), pp. 15-28. 
del mismo, por ello la decisión de la autoridad o su sola representación constituyen, en no pocas ocasiones, la brújula de aquella actividad ${ }^{105}$.

La actividad judicial o las decisiones de autoridad, en general, dirigen la vida negocial del pueblo eliminando aquellas prácticas privadas que conculcan el orden social o las instituciones. En todo caso, las cláusulas, cautelas, relaciones jurídicas o las instituciones alumbradas por los juristas prácticos serán consideradas jurídicas en virtud del juicio de valor del juez o autoridad acerca de su adecuación a la finalidad ética intrínseca al derecho: su justicia. Es más, los contratos o negocios jurídicos que están destinados a identificarse de manera ordinaria con una institución concreta exigen que se compruebe esta adecuación y apreciar si no se trata de una simulación, de un fraude de ley o de un abuso del derecho.

3. ¿Tiene encaje positivo esta doctrina del derecho institucional? Hemos visto al inicio de este estudio que Roca Sastre buscaba en los principios generales del derecho, dado su carácter informador del ordenamiento jurídico, el fundamento del derecho institucional (art. 1.4 del Código Civil). Si bien, es cierto que cada institución en tanto unidad de sentido encierra la materialización de un principio jurídico o pauta de valor, no creo que sea útil a la ciencia jurídica confundir la institución con los principios generales del Derecho, máxime cuando hay otros preceptos del Código Civil donde encontrar un encaje más perfecto de la idea de derecho institucional, veámoslo:

- Art. 3.1. Código Civil. «las normas se interpretarán según el sentido propio de sus palabras, en relación con el contexto, los antecedentes históricos y legislativos, y la realidad social del tiempo en que han de ser aplicadas, atendiendo fundamentalmente al espíritu y finalidad de aquéllas». A mi juicio y siguiendo la enseñanza de Vallet, si la tarea del intérprete consiste en averiguar la «cosa o imagen» de la que habla el texto legal, esto supone necesariamente conocer la institución a la que se refiere. Es decir, el derecho institucional puede ser considerado la semántica del texto legislado, en la medida que revela el orden ontológico de lo jurídico. la interpretación, así entendida, es un proceso de comprensión que irá desvelando, entre las sombras del ser y el acontecer, la naturaleza de la cosa, para, desde ella, guiar nuestra decisión.

105 DíEz Picazo, L., Experiencias jurídicas y Teoría del Derecho, Ariel, Madrid, 1973, pp. 10-25. 
- Art. 4.1 Código Civil. «Procederá la aplicación analógica de las normas cuando éstas no contemplen un supuesto específico, pero regulen otro semejante entre los que se aprecie identidad de razón». La analogía no sólo se trata de un estudio acerca de la similitud de los hechos (juicio fáctico) también se trata de un juicio valorativo acerca de la existencia de una «identidad de razón» entre los mismos. Si se entiende la institución jurídica como unidad de sentido, lógicamente será en el derecho institucional donde encontremos ese «logos» desde el que integrar los hechos (ontos).

Del mismo modo, si nos ocupamos de la interpretación de los negocios jurídicos se puede encontrar abrigo a los postulados del derecho institucional, por ejemplo:

- Art. 1283 Código Civil: «Cualquiera que sea la generalidad de los términos de un contrato, no deberán entenderse comprendidos en él cosas distintas y casos diferentes de aquellos sobre los que los interesados se propusieron contratar».

- Art. 1286 Código Civil. «Las palabras que puedan tener distintas acepciones serán entendidas en aquella que sea más conforme a la naturaleza y objeto del contrato».

- Art. 1287 Código Civil: «El uso o la costumbre del país se tendrán en cuenta para interpretar las ambigüedades de los contratos, supliendo en éstos la omisión de cláusulas que de ordinario suelen establecerse».

De la lectura de estos tres artículos (de naturaleza imperativa según el legislador) se puede observar que el llamado derecho institucional ocuparía un lugar preponderante en la interpretación correctora e integradora de los negocios jurídicos, tal y como señalaron en sus obras Roca Sastre y Vallet de Goytisolo.

4. Vallet es un filósofo privatista y estas convicciones ius privatistas influyen también en su filosofía política y social. La filosofía del derecho española ha centrado su atención tradicionalmente en el derecho público ¿Por qué no buscar una nueva vía de desarrollo en reconocidos privatistas como Castán Tobeñas, De Castro, Hernández Gil, Roca Sastre, Díez Picazo, Puig Brutau y Vallet de Goytisolo? No sería aventurado afirmar que estos maestros españoles del Derecho civil contribuyeron al desarrollo de la metodología jurídica en España con obras de gran magnitud, que aún hoy son referencia obligada en todos los centros universitarios y con cuya lectura nos 
hemos cultivado ${ }^{106}$. No es atrevido afirmar que estos civilistas desembocaron en lides más próximas a la Filosofía del Derecho que al derecho positivo. Creo que sería un nuevo e interesante camino explorar las implicaciones filosóficas de nuestros geniales privatistas. ¿Por qué no recordar el valor de estas obras, las cuales supieron trascender el derecho positivo y ofrecer nuevos rumbos a la ciencia jurídica?

106 Castán Tobeñas, J., Teoría de la aplicación e investigación del Derecho, Reus, Madrid, 2005; De Castro y Bravo, F., El negocio jurídico, Instituto Nacional de Estudios Jurídicos, Madrid, 1971; Hernández GIL, A., Metodología de la Ciencia del Derecho, Obras Completas, vol. V, Espasa Calpe, Madrid, 1988; Roca Sastre, R. y Puig Brutau, J., Estudios de derecho privado, AranzadiThomson Reuters, Navarra, 2009; DíEz PICAZo, L., Experiencias jurídicas y Teoría del Derecho, Ariel, Madrid, 1973; Puig Brutau, J., La jurisprudencia como fuente del derecho, Bosch, Barcelona, 2006; Vallet De Goytisolo, J., Metodología de la ciencia expositiva y explicativa del Derecho. Parte sistemática, tomo II, vol. I, Fundación Cultural del Notariado, Madrid, 2002. 